\title{
Investigation of space charge in low-density polyethylene using a field probe technique
}

\section{Khalil, M. Salah; Hansen, Bo Svarrer}

Published in:

IEEE Transactions on Electrical Insulation

Link to article, DOI:

$10.1109 / 14.2385$

Publication date:

1988

Document Version

Publisher's PDF, also known as Version of record

Link back to DTU Orbit

Citation (APA):

Khalil, M. S., \& Hansen, B. S. (1988). Investigation of space charge in low-density polyethylene using a field probe technique. IEEE Transactions on Electrical Insulation, 23(3), 441-445. https://doi.org/10.1109/14.2385

\section{General rights}

Copyright and moral rights for the publications made accessible in the public portal are retained by the authors and/or other copyright owners and it is a condition of accessing publications that users recognise and abide by the legal requirements associated with these rights.

- Users may download and print one copy of any publication from the public portal for the purpose of private study or research.

- You may not further distribute the material or use it for any profit-making activity or commercial gain

- You may freely distribute the URL identifying the publication in the public portal 


\title{
Investigation of Space Charge in Low-Density Polyethylene Using a Field Probe Technique
}

\author{
M. Salah Khalil \\ Electric Power Eng. Dept., Technical University of \\ Denmark \\ and Bo Svarrer Hansen \\ NKT Power Cables, Denmark
}

\begin{abstract}
Field distortion caused by space charge accumulation in solid insulations represents one of the problems of extruded HVDC cables. The present paper describes a special test method, using a capacitive field probe, in investigating the space charge distribution in low-density polyethylene (LDPE). Specimens of $7 \mathrm{~mm}$ thickness were stressed under $100 \mathrm{kV}$ de at room temperature and for different time periods. The results indicate that the (LDPE) insulation layer between electrodes is occupied by positive and negative homocharges. The dependence of space charge distribution on the stressing time is also evident.
\end{abstract}

INTRODUCTION

$\mathrm{D}$ ESPITE the well known advantages of polymer insulated HVDC cables in comparison with oil-filled and paper insulated cables, such cables do pose some problems to cable designers and insulation scientists [13]. One of these problems is the space charge accumulation in the insulation. When insulating polymers are subjected to an electric field, the formation of space charges causes a redistribution of the potential in the gap between the electrodes so that the actual field to which the polymer is subjected will differ markedly from the geometric field. The cumulative effect of space charge accumulation in the insulation and the possible polarity reversal of the power flow in polymer insulated HVDC cables usually leads to a considerable deleterious effect on their breakdown strength.
There exist very few papers dealing with space charges in solids, due to the fact that direct space charge measurements usually entail difficulties of execution and of interpretation [4]. For the direct experimental determination of the distribution and type of charges (homo or hetero), two methods have been used, the pressure wave propagation [5], and the dust figure technique [6]. Apart from these methods, most of the published investigations of space charges in polymers use indirect methods and depend on the measurement of current or voltage in an external circuit [7]. Field-probe techniques have been known for many years for measuring surface charges on thin films of solid insulations [8-11]. In the present paper, a new direct method for investigating space charges in LDPE, thick specimens is introduced using a capacitive field probe.

$0018-9367 / 88 / 0600-44181.00$ (C) 1988 IEEE 


\section{EXPERIMENTAL DETAILS}

7 EST specimens were made of LDPE of density 0.92 $1 \mathrm{~g} / \mathrm{cm}^{3}$. The specimens were cylinders with a diameter of $36 \mathrm{~mm}$. Two hemispherically tipped stainless steel electrodes of $20 \mathrm{~mm}$ diameter were inserted from both ends such that $7 \mathrm{~mm}$ existed between their tips, as shown in Figure 1.

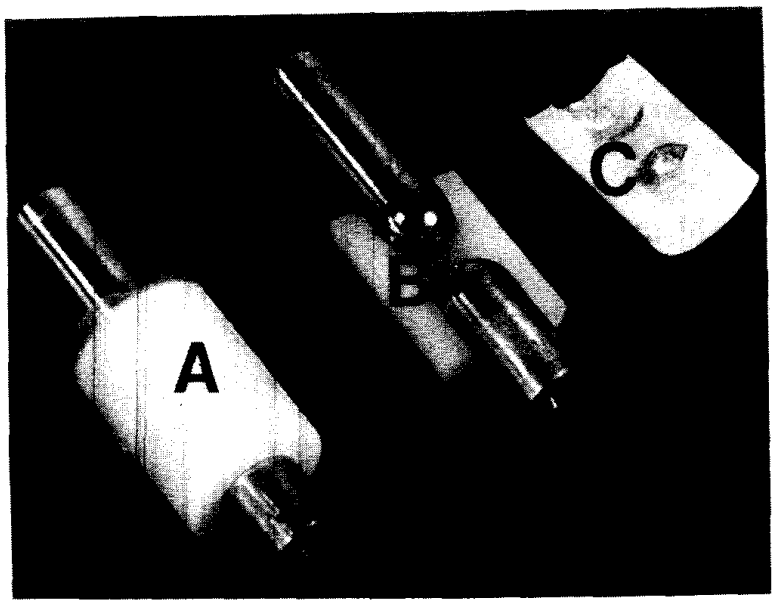

Figure 1.

Test specimen. (A) Specimen with electrodes. (B) Section in specimen with electrodes. (C) Section in specimen with electrodes removed.

Specimens were placed in a Perspex ${ }^{\text {TM }}$ test vessel and immersed in silicone oil. A $100 \mathrm{kV}$ dc voltage was applied between the electrodes for different time durations ranging from $30 \mathrm{~min}$ up to $144 \mathrm{~h}$. The voltage was then removed and both electrodes pulled out. Immediately afterwards, specimens were cut along the cylinder axis into two identical halves using a sharp-edged knife. The cut specimen was then fastened on a mobile table guided under an electrostatic field probe with its cut surface directed towards the probe, Figure 2.

The probe was a screened and Teflon ${ }^{\mathrm{TM}}$ insulated 0.9 $\mathrm{mm}$ diameter copper wire, made flush to a brass circular screen of $5 \mathrm{~cm}$ diameter. The measured capacitance of the probe was about $5 \mathrm{pF}$. The probe was connected to an electrometer (Keithley 610-C), through a coaxial cable. The gap between the specimen surface and the probe, which was used through the present experiments, was $0.75 \mathrm{~mm}$ and was adjusted using a micrometer mechanism allowing movement of the probe together

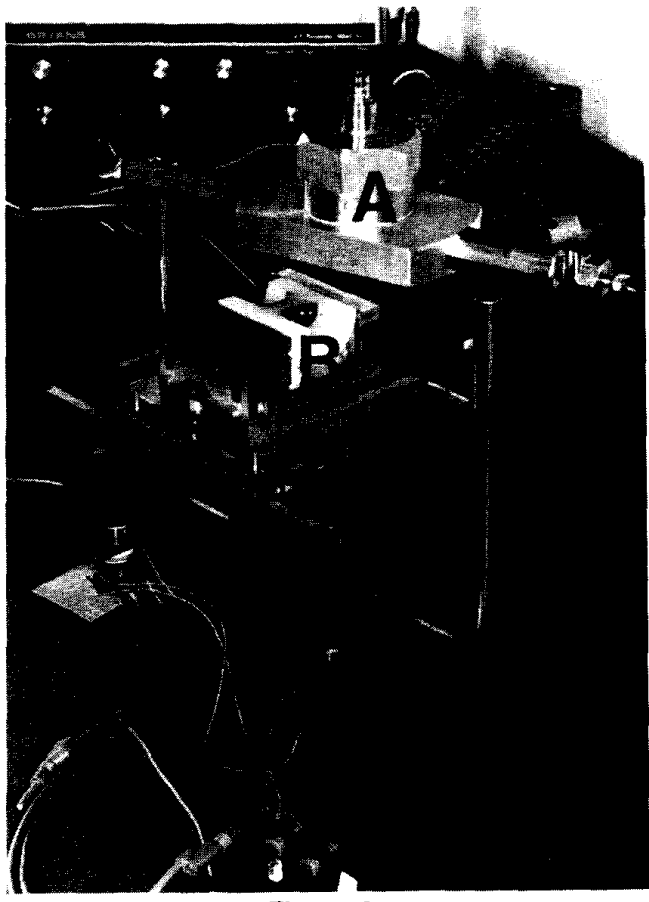

Figure 2.

Specimen holding equipment, movable table, and probe. (A) Probe. (B) Test specimen. (C) Clamp. (D) Movable table. (E) XY potentiometers.

with its screen in a direction perpendicular to the specimen surface. Calibration of the probe shows that this gap length falls within the limits at which the induced charge on the probe varies linearly with the voltage on the surface of the probe. The position of the manually driven table was monitored by two linear potentiometers $X, Y$. The output of the X potentiometer was used to drive the $x$-deflection of an XY-recorder while the output of the $Y$ potentiometer superimposed by the output of the electrometer through a differential amplifier was used to drive the $y$-deflection of the XY-recorder.

The experimental arrangement is shown in Figure 3. This arrangement allows measurement of the induced potential on the probe which is a measure of the effective surface charge density of the surface of the specimen. The theory of the measuring system is given elsewhere [8-12].

In order to establish the sign of the charge, a simulating specimen has been made. This has been achieved by implanting a group of copper wires on the edge of 


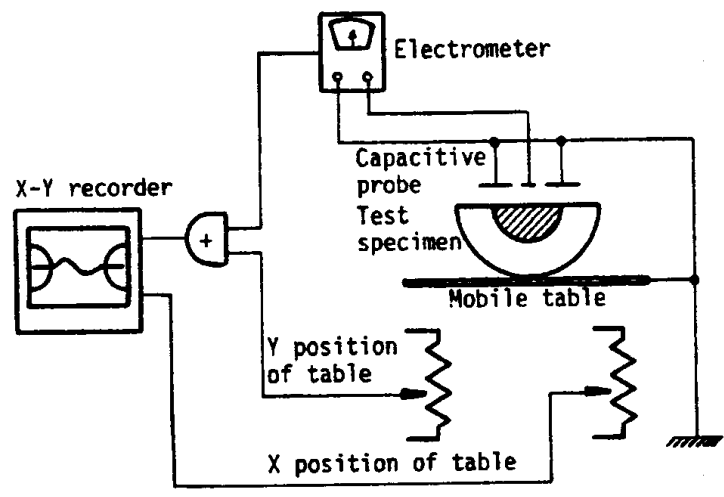

Figure 3. Experimental arrangement.

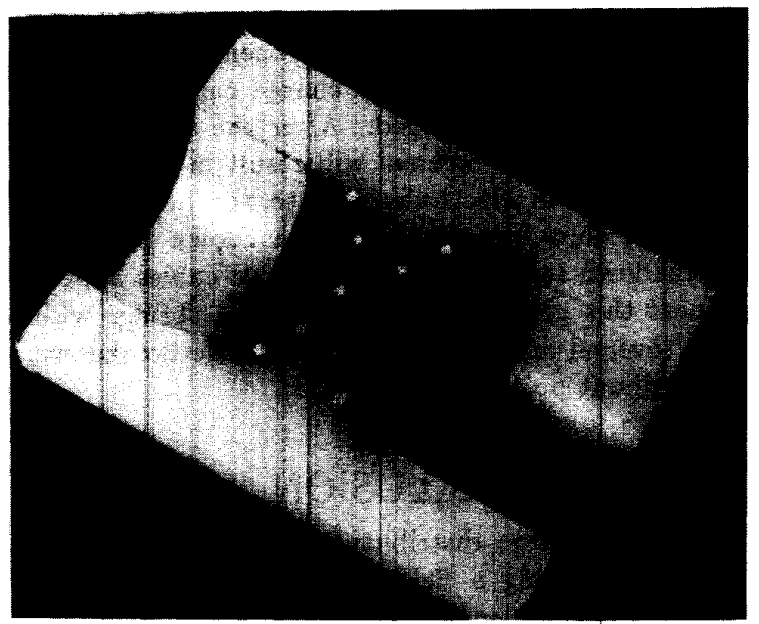

Figure 4. Specimen with copper wires.

each electrode. The wires were made flush with the specimen surface as shown in Figure 4. Voltage of different dc polarity was applied to the wires while the induced voltage resulting from such a specimen was recorded. The measured potential distribution from this experiment is shown in Figure 5 with the wires made positive and negative on each group of wires. The distribution is very similar to the distribution resulting from specimens charged for $24 \mathrm{~h}$ and more as can be seen in Figure 6 .

Application of negative polarity to one group of wires gave a distribution which was almost similar to the distribution resulting from a charged specimen for $30 \mathrm{~min}$ and $3 \mathrm{~h}$ with the exception of the absence of

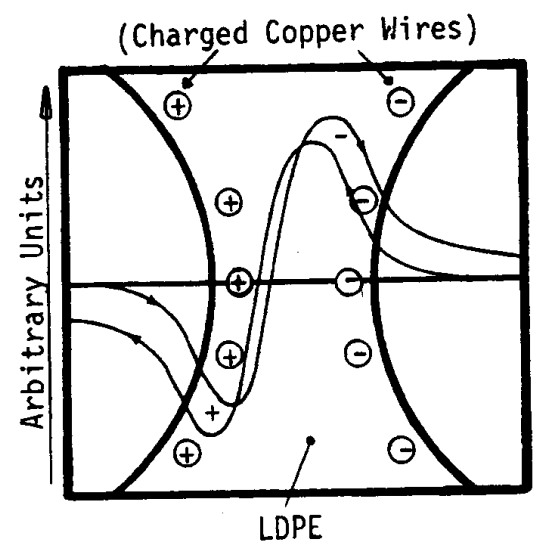

Figure 5.

The induced probe potential measured with $\pm 100 \mathrm{~V}$ applied to the copper wires.

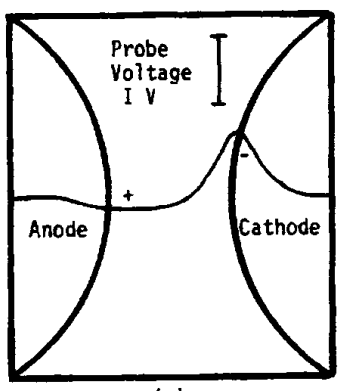

(a)

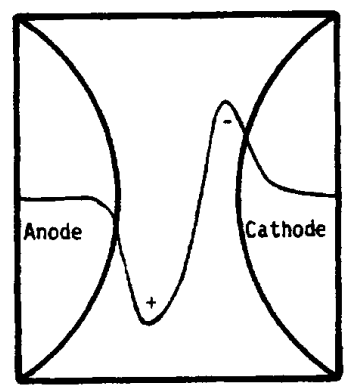

(c)

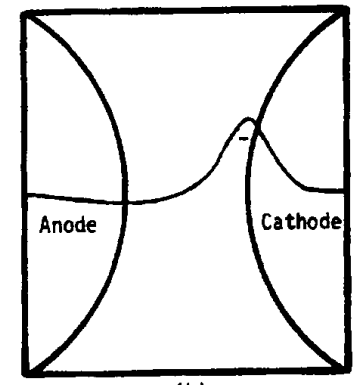

(b)

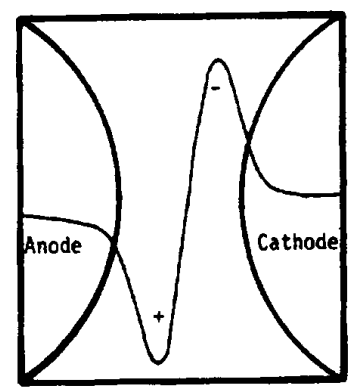

(d)
Figure 6.

Variation of probe potential after various stressing times. Stressing voltage $+100 \mathrm{kV}$ dc. $t_{s}$ : stressing time. (a) $t_{0}=30 \mathrm{~min},(b) t_{0}=3 \mathrm{~h}$, (c) $t_{\mathrm{d}}=24 \mathrm{~h}$, (d) $\mathrm{t}_{\mathrm{s}}=144 \mathrm{~h}$.

charge accumulation at the anode. The similarity sug- 
gests that a signal above the vertical line indicates the presence of negative charges To check whether the accumulated charge changes during the time which elapses between stress interruption and sectioning of the sample and the procedure of field recording, measurements were repeated on the same specimen for various time periods after stress removal ranging from a few minutes up to several days. It was found that, as long as the specimen was kept at room temperature, the recorded field distribution did not change appreciably during the first $3 \mathrm{~h}$. This is in agreement with the findings in the literature [3] where it is well established that in LDPE, and at room temperature, space charges can persist for hours.

\section{RESULTS AND DISCUSSION}

$\Lambda \mathrm{s}$ shown in Figure 6, after 30 min negative charges $A$ are formed in the immediate vicinity of the cathode and positive charges at the anode. The magnitude of the accumulated negative charges is much higher than that of the positive charges at the anode. Such a situation is almost the same for a stressing time of $3 \mathrm{~h}$. However, after $24 \mathrm{~h}$, the positive space charges at the anode increase significantly while there is a small increase in the negative charge at the cathode resulting in a symmetrical homocharge distribution. For stressing periods more than 24 to $144 \mathrm{~h}$, there is no significant change in the general pattern of the charge distribution. To date, there has been no universally accepted explanation of the nature and origin of charge carriers as well as the mechanisms of their transport in polymers. However, conduction, mobility and thermally stimulated currents (TSC) measurements of many workers [12-15], imply the following:

1. electrons are injected at the cathode and holes are injected at the anode

2. charges are generated within the polymer itself from localized donor or acceptor states.

Such states are due to several factors such as chain branching, impurities and structural anomalies. Localized states act as carrier traps which are capable of providing conduction charges as well as long-term charge storage. It has also been shown that the charge injected by an applied field into a polymer in contact with a metal surface is time dependent [15]. Recent probe measurements [16] on charge transfer at metal polyethylene interfaces have shown that the charges injected in the polymer have the same sign as that of the injecting electrode (homocharges). The fact that a metal electrode will inject charge carriers into the bulk material even in the absence of an applied field, has long been known [15-17] although not generally recognized as important in high-field breakdown studies. With a negative potential applied to an electrode, charge injection can be greatly enhanced whereas at an anode, a considerable positive potential must be applied for a longer period, before the previously accumulated negative charge is neutralized and positive charges appear at the interface. The present results seem to correlate with this picture. Thus after $30 \mathrm{~min}$ of voltage application, a negative space charge initially forms in the vicinity of the cathode, while a small positive space charge appears at the anode. As the stressing time increases, a similar positive charge appears at the anode and an equilibrium is attained after the neutralization of the negative charge there. The present space charge measurements give a resultant charge distribution in the sense that although positive space charge may be neutralized by a negative charge, recombination need not necessarily occur and both types of charges may coexist [16]. The space charge distribution remains 'frozen in' indicating that the positive and negative charge carriers (whatever their origin) are trapped. After the steady state is reached, a polarity reversal will result in stress concentration at both electrodes due to the homocharge distribution, thus increasing the breakdown probability. Breakdown tests of PE insulated dc cables appear to support this picture as the breakdown voltage with polarity reversal amounts to $70 \%$ of the dc breakdown voltage without polarity reversal [18].

\section{CONCLUSION}

$\mathrm{T}$ HE space charge distribution in LDPE has been elucidated using a field probe technique. Space charges in LDPE under the present conditions consist of homocharges. This distribution is consistent with other results concerning the mechanism of charge carrier formation and transport in polymers. It is also supported by results concerning breakdown in dc cables.

Further work should be carried out to find suitable additives which can be used in order to eliminate the effect of space charges in polymer insulated dc cables. Finally, it has been shown that the field probe technique is an effective method for investigating space charges in solid insulators.

\section{ACKNOWLEDGEMENTS}

$T$ HE first author is grateful to the Electric Power Engineering Department, Technical University of Denmark and NKT Power Cables for experimental facilities and materials. 


\section{REFERENCES}

[1] A. Bradwell, R. Cooper, and B. Varlow, "Conduction in Polyethylene with Strong Electric Fields and the Effect of Prestressing on the Electric Strength", Froc. IEE, Vol. 118, No. 1, pp. 247-254, 1971.

[2] K. Yoshida, "Research and Development of HVDC Cables in Japan", CIGRE Report 21-03, pp. 1-14, 1974.

[3] N. Ando, "Development of $\pm 250 \mathrm{kV}$ dc Crosslinked Polyethylene Cable", Hitachi Review, Vol. 25, No. 10, pp. 355-360, 1976.

[4] Z. Croitoru, "Space Charges in Dielectrics", Progress in Dielectrics, Vol. 6, pp. 105-145, 1965.

[5] F. Chapeau, C. Alquie and J. Lewiner, "The Pressure Wave Propagation Method for the Analysis of Insulating Materials: Application to LDPE used in HV cables", IEEE Trans. Electrical Insulation, Vol. 21, No. 3, pp. 405-410, 1986.

[6] G. M. Sessler, "Topics in Applied Physics", Vol. 33, Springer Verlag, pp. 39-50, 1980.

[7] J. Perret and R. Fournie, "Space Charge in Polyethylene for High Voltage Cables", IEE Conference Publication No. 129, Dielectric Materials, Measurements and Application, pp. 83-86, 1975.

[8] D. K. Davies, "The Examination of the Electrical Properties of Insulators by Surface Charge Measurements", J. Sc. Instrum., Vol. 44, pp. 521-524, 1967.

[9] T. R. Foord, "Measurement of the Distribution of Surface Electric Charge by Use of a Capacitive Probe", J. Phys. E: Sci. Instrum., Vol. 2, pp. 411$413,1969$.

[10] H. J. Wintle, "Theory of the Potential Probe Used in Static Electrification Measurements on Insulators", J. Phys. E: Sci. Instrum., Vol. Vol. 3, pp. 334336, 1970.

[11] G. M. Sessler and J. E. West, "Method for Measurement of Surface Charge Densities on Electrets", Rev. Sci. Instrum., Vol. 42, pp. 15-18, 1971.

[12] R. V. Olhausen and G. Sachs, "AC Loss and DC Conduction Mechanisms in Polyethylene Under
High Voltage Electric Fields", IEE Proc. Pt. A., Vol. 128 , pp. 183-192, 1981.

[13] M. Ieda, "Electrical Conduction and Carrier Traps in Polymeric Materials", IEEE Trans. Electrical Insulation, Vol. 19, No. 3, pp. 162-178, 1984.

[14] T. J. Lewis, "Charge Transport in Polymers", Annu. Rep. Conf. Electrical Insulation and Dielect. Phenomena, Ntl. Acad. Sci., Washington D.C., pp. 533$561,1976$.

[15] D. K. Davies, "Field Stimulated Interfacial Electron Transfer", IEE Proc. Pt.A., Vol. 128, pp. 153-158, 1981.

[16] T. J. Lewis, R. Toomer and C. Barnes, "Charge Transfer at Metal Dielectric Liquid Interfaces, Evidence from the Solid State", J. Electrostatics, Vol. 12, pp. 459-468, 1982.

[17] T. J. Lewis, "The Role of Electrodes in Conduction and Breakdown Phenomena in Solid Dielectrics", IEEE Trans. Electrical Insulation, Vol. 19, pp. 210216, 1984.

[18] Y. Sekii, "Electrical Characteristics of Extruded Insulation DC Cables", CIGRE Report WG 21-01, pp. $1-9,1982$.

This paper was presented at the IEEE International Symposium on Electrical Insulation, Montreal, Canada, June 1984.

Manuscript was received on 8 Feb 1985, in final form 19 Apr 1988. 